\title{
The Development of the Overseas-study Policy from the Foundation of the PRC to Now
}

\author{
Chuntao Zhou \\ Jilin agricultural university, International education and exchange college, Jilin, Changchun130118 \\ hunter2011@foxmail.com
}

Keywords: Public policy, Overseas-study policy, Evolution.

\begin{abstract}
Overseas-study talents are the important component of national talents. Overseas-study policy is the important component of public policy. National overseas-study policy affects the talent construction of our country. From the foundation of the PRC to now overseas-study policy of our country has changed constantly with the change of national interior environment and foreign policy. The overseas-study policy reflects the degree of opening to the outside world in China, the relationship with the international strong countries as well as the situation of filling the talents of our country. We comb the various meetings and talks about overseas study from the foundation of the PRC to now, and according to the historical background we analyze the formation, change and development of the overseas-study policy in this paper.
\end{abstract}

\section{The Significance of Studying Overseas-study Policy}

Since the first overseas-study student Rong Hong on a government sponsorship has been sent to Yale University in the modern times, the overseas study with a history of hundreds year which makes us study from the world advanced education to save or rejuvenate a country is opened. Senting the students abroad to study is the important way of training the talents for our country. Chin's talents reserve status, the structure of talents in our country, especially the development of China's higher education level affects the establishment of the overseas-study policy. Studying the overseas-study policy has a profound practical significance for cultivating the talents, give full play to talents effectiveness and realizing the transformation of overseas-study achievements. The overseas-study students are important resources of our country. They have played an important role in the country's construction.[1]

The Safety of National Talents. One of principles for overseas-study policy is to ensure the safety of national overseas-study talents. Under the open talents concept we set up safety crisis consciousness for overseas-study talents. Overseas-study policy should ensure "the safety of overseas-study talents". Talents resource competition of European and American strong countries under the background of globalization and the social atmosphere of some Chinese people emphasizing on the material interests too much have caused a great threat to the safety of overseas-study talents in China. How to ensure that the overseas-study talents of China, the top talents among them, serving for the country are a serious subject in reality. For example, in the early days of new founding of China the policy is "strict selection, less rather than abuse"(from 1950 to1953). After the reform and opening to the outside world, the policy is "seize the opportunity to actively select, broaden the channels to strive for sending more, take science and technology as the main and take into account others" (1979). These policies reflect that the urgent lacking situation of our country needing the talents in the different periods [2].

The Rational Use of Overseas-study Talents. The investment of overseas study sent by the government belongs to the public behavior. The overseas-study talents with the service of returning to our country belong to the state-owned assets. By making the reasonable policy, we can build the overseas-study talents archives, improve the talents introduction mechanism, and create an environment to play its ability. Formulate the policy in line with the development strategy of China's development strategy and the law of the talents flow with high intelligence, and combine the national interests with the individual interests. 
For example, "create a good working environment and living conditions, broaden the scope of employment and implement the talents flow"(1988).

The Diplomatic Significance of Overseas Study. The communication of overseas-study students is the vanguard of foreign exchange. The important events in the overseas-study history often rely on important diplomatic events. In the situation of folk diplomacy booming, the exchanging students can promote the exchanges between the nations, and can cultivate a group of angels who build a bridge of friendship between the two countries, and can eliminate misunderstanding, promote the cooperation and realize the achieve overseas-study diplomacy. The leaders of the two countries meet each other and sign the agreements on economic and trade and education. They make the political dialogue, at the same time they will refer to the exchange of culture, education, science and technology and social development much more.

\section{The Overview of Overseas-Study in All Periods of the New China}

Experts and scholars takes the divide methods in different age backgrounds to overseas-study that is government sponsored in all time stages of the new China. Referring to the historical stage that taken by comrade Songjian who is former state councilor and lady Yang Xinyu who is vice secretary of national scholarship fund, in according to important historical transition periods and symbolic events, this article divides the new China into several periods that followed.[3]

The Foundation of the PRC and the Evolution of Ties between the Soviet union and New China. At the year of 1949, the new China established. A thousand things waited to be done, and the new China took the policy of leaning one sided to the Society union. The main overseas-study country was the Soviet union and eastern Europe countries. Prime minister Zhou Enlai made a speech at May,10,1957, which indicated that ' do not concern the earlier or the later of returning to country, all of overseas-students treated equally and they had the liberty to return to country or go to overseas'. Because overseas student needed to promote their ability of language before went to overseas, therefore, the training base of overseas student was established, which was based on language university. At the beginning of foundation of the PRC, the students who were picked up for nation-building were mainly science and engineering students. As the ties between the Soviet union and China became worse, the withdrawal of experts from the Soviet union caused that the policies of overseas-study changed, and the Soviet union was not the destination country of overseas study afterwards.

The Great Cultural Revolution. In the period of the great cultural revolution( from 1966 to 1977), the diplomacy of our nation was closed, the domestic economy was stagnated, and the orders of education was disorderly. During this period, the policy of 'stop to elect the party of ting' had lasted up to six years. The policy-making was serious and struggling. With the establishing

diplomatic relationship with Italy and Canada, a few students were sent to western country. For example, at the year of 1973, with concerns of prime minister Zhou Enlai, our country had a project of scholar exchanging with Canada's government, this project has executed for forty years. In the middle period of the great cultural revolution, our country sent a few students to Japan, Egypt, France and England for learning. The main aim was to cultivate the personnel in charge of foreign affairs, and the majority of these students went to learn foreign language, the minority went to learn science.[4]

The Reform and Open-up Policy and Sino US Diplomatic Relations. The reform and open-up policy saved the fate of Chinese unrest, and found the roads of Chinese development, glowed the national confidence again. US has the most advanced higher education, and Sino US diplomatic relations had the significant meaning for the overseas-study students who want to go to US to study.

First, in the year of 1978, the dressing of omrade Deng Xiaoping determined the basis of later overseas-study policy, which roughly was to 'send thousands upon thousands of students to overseas'. In November of 1984, the state council held the meeting of jobs for the personnel to go to overseas to study countrywide.

Second, the ties between China and US became important ties for the world gradually. At December, 26, 1978, after the foundation of the PRC, the first group of students sent by government 
were 52 persons. At May, 25, 2010, both China and US established the top-level consultation mechanism of cultural and educational exchanges, and implemented 'one thousand peoples plan', which was scheduled to send ten thousand US students to China for study within four years. During the period, comrade Xing Jinping visited the US in the year of 2012, and the US secretary of state Hillary expressed in her addressing that the benifits of the plan for sending ten thousand US students to China would be enjoyed by people in their whole life.

Since New Century. Since new century, in the background of the great renaissance of Chinese nation and globalization, more and more people go to overseas to study. Therefore, the structure formed. The structure takes sending by government as the main leading, and takes overseas-study at person's own expense as main body.

First, in the year of 2002, the state council takes 'the strategy of reinvigorating China through human resource development', and encouraging the personnel who study at overseas to return to work. In February, 2003, twelve ministries and commissions jointly made " the System of the Inter Joint Ministerial Meetings for the Works for the Return of Personnel who Study at Overseas" with the aim of building the environment of attracting the personnel who study at overseas to return, and attracting them to return to devote to the nation. In December of 2003, the state council issued that the determination of further strengthening talents works, and put forward that increasing the efforts of attracting talents study at overseas and overseas talents with top level. The coordination group of national talent work aimed at the condition of high detention rate of top talents in our country's science and engineering domain, and the central organization department implemented in 2008 'thousands of people plan' to attract overseas talentswith top level.

Second, as the investment of national foundation for overseas study increases gradually year by year, the manage committee of national foundation for overseas study has been established in the year of 1996. It is a member of education department, and is specially in charge of government-sponsored overseas-study. At present, the sponsored objects have covered all of visiting scholars, doctors, masters, and bachelors. The foreign regulatory information network of Education Ministry of the People's Republic of China is established, and it is managed by international exchange and communication department of education ministry. Since 2003, this network has published the lists of authorized university at overseas, and issued the early warning of overseas-study.

\section{The Development Features of Overseas-Study Policies in Our Country within this Sixty Years}

The overseas-study policies within this sixty years reflect on the complicated and struggling state-building. With increasing deepening of open-up policy and the promotion of comprehensive state strength, the overseas-study policies transform from natural science to humanity culture, and the both are important. We have made the transformation from single nation to all of nations worldwide, from serious political examination to loose examination, from single sending to mutual sending, from low rate of return to high rate of return, and from overseas study with high age to overseas study with low age. That presented the booming of overseas study at person's own expense, and the phenomenon of the plebification and the legalization of overseas study.

The Booming of Overseas-Study at Person's Own Expense. During the period from the year of 1949 to the year of 1978, the number of personnel overseas study at his own expense is almost zero. Since the open-up policy, the state council released in the year of 1980 " the Contemporary Provisions on Overseas Study at Person's Expense", which indicated that the nation treats equally lied in politics to overseas study at person's own expense and the personnel overseas study at public expense. The people who have overseas study at person's own expense have increased, the talents who have the experience of overseas study and are used by the nation are not only sent by government. For example, 'treating equally in politics to the personnel who have overseas study at person's own expense and overseas study at public expense, but having certain limits in application '(1981), ' there is not any limit to personnel who have overseas study at person's own expense if its procedure is legal' (1984), 'reclaiming the intermediate market of overseas study at person's own expense, and implementing the early warning and supervision'(1999), establishing 
national scholarship for superior personnel who have overseas study at person's own expense(2003).

The Features of Overseas-Study at Present. Europe, America and Australia are main destination country for overseas study at present. As the countries in Asia, Africa and south America, overseas-study have transformed from a few persons to the gradual rise of persons, and it has entered the prosperous development period, but it has not reached 'overseas-study popularly'. And it also can call the plebification of overseas study.[6] For example, the education department took the policy of 'Three Superiors' in 2005, and it was scheduled to reach six thousands person in 2013. More persons from average family have benefited from it. Rural person studied for doctors, who are sponsored by government through ' the Project of Cultivating Top Level Graduate Students Sent by Government'. On the background of the overseas-study person sent by government increasing, it is necessary to concern the benefits of overseas study, to make sure that we guarantee national investment to have efficient output, to cultivate many talents who are needed badly in state-building.

The Trend of Overseas-Study Legalization. Overseas study sent by government presents the trend of legalization after the establishment of national scholarship commission for overseas study . For example, to formulate the policy of 'personal application, expert evaluation, competition equally, enrolling the superior, sending with contract, compensating for the breach'(1996). National scholarship commission for overseas study has realized high rate of return through signing agreement, sending with contract, compensating for the breach, it is also a progress of overseas-study legalization. It has been revised and cleared especially for certain sensitive problems. For example, we implement new supportive policy and the policy of 'exemption'for the remained overseas-study people who are not concerned by government except for the people in the plan. We will revise and define them continuously in the form of policies and laws.

\section{References}

[1] Z.P. Wang. The Group Differentiation of Overseas-Study Student and the Evolution of Social Ideological Trend. Jilin people's Publishing House.

[2] X.F. Chen, C.G. Chen. The Research Report of Assessment in Benefits of Overseas-Study Sent by Government since the Revolution and Open-up.Peking University.

[3] D.G. Miao. The Sixty Years of Overseas-Study.Cent ral Party Literature Press.

[4] D.G. Miao, Chengxi. 1949-2009:The Development, Current Situation and Trend of Chinese Overseas-Study Policies(First Half). The Learned Journal of Xuzhou Normal University(Philosophy and Social Science Edition), the Second in 2010. 